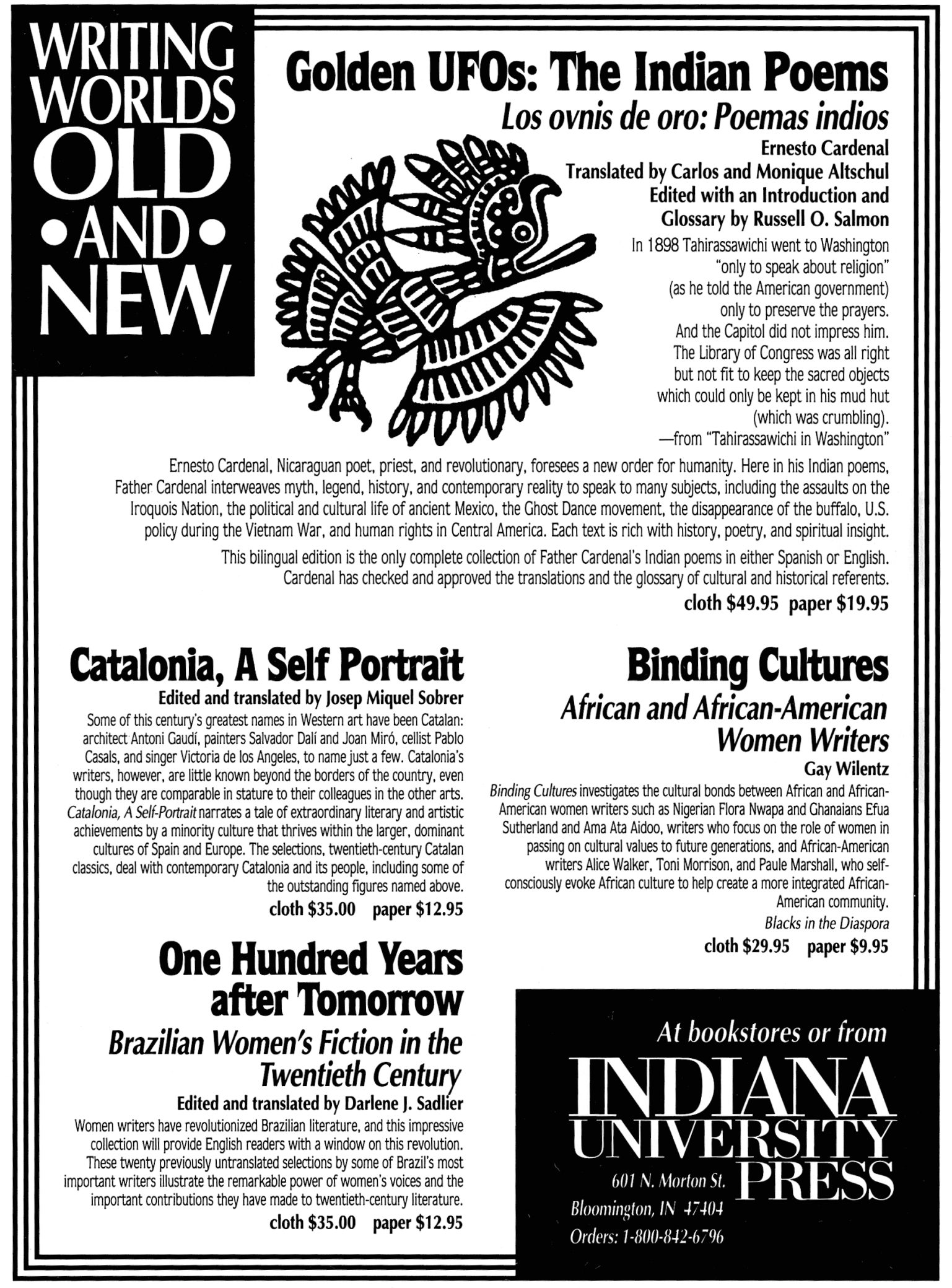




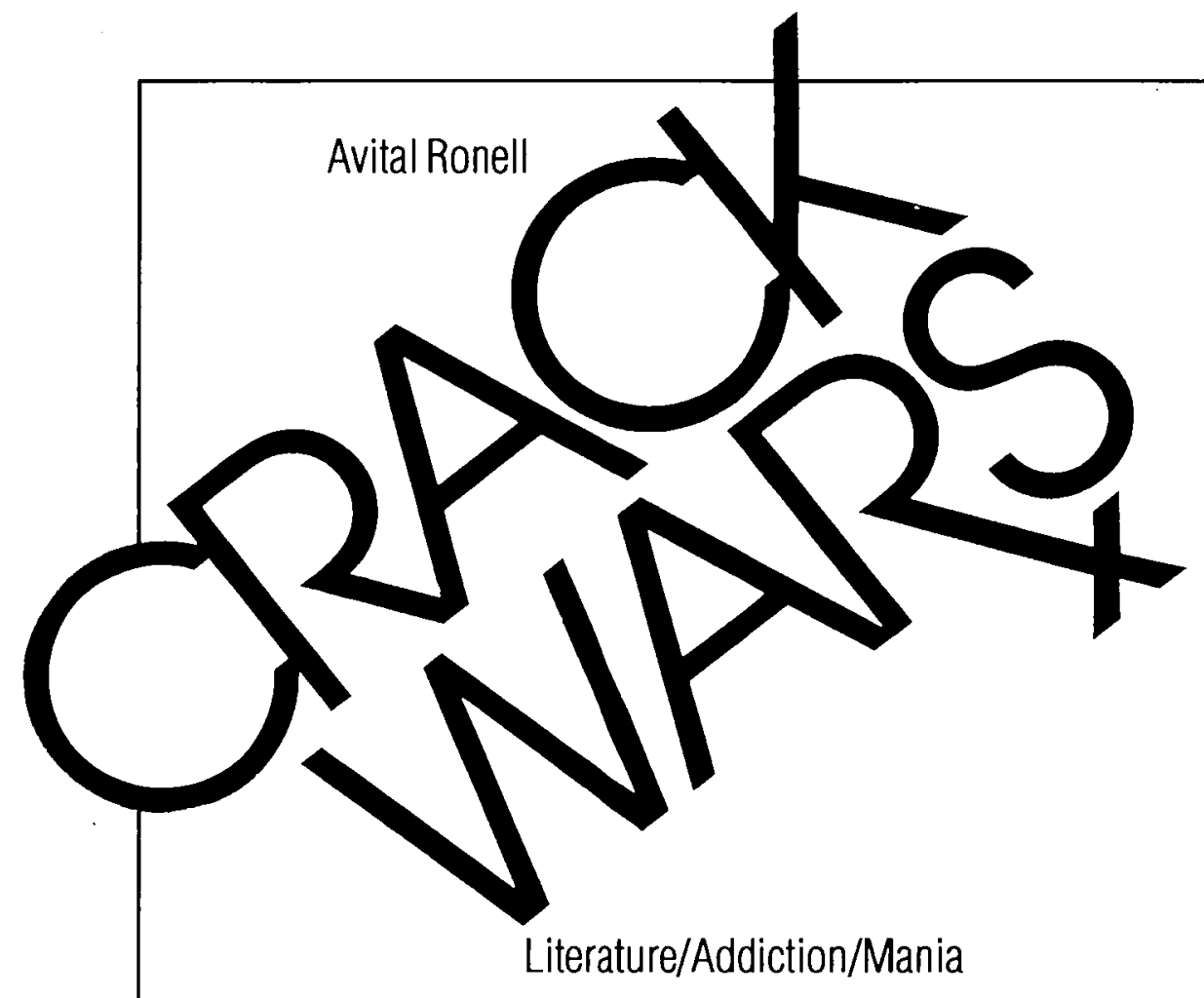

"This is a very important book, raising the question of addiclion and self-destruction seriously from a philosophical point of view." - Sander L. Gilman, author of Disease and Representation (1988). Crack Wars demonstrates that addiction has been inspired and supported by a culture that is itself dependent upon the creation of destructive desires. Ronell appeals to literature as the most advanced and sensitive measure of this immensely difficult dilemma. $\$ 25.00$

\section{Agonies of the Intellectual}

Commitment, Subjectivity, and the Performative in the Twentieth-Century French Tradition

Allan Stoekl

"A long-duration intellectual history - smart, patient, beautifully constructed. " - Alice Yaeger Kaplan, Duke University. In Agonies of the Intellectual Allan Stoekl differentiates the modern intellectuals from the older traditions of priests, philosophes, and academics and lakes a hard look al the difficult intersection of thought and act: decision. Available April. $\$ 40.00$

\section{To Criticize the Critic and Other Writings}

\section{T.S. Eliot}

"This volume covers almost the whole range of Eliot's development and at the same time gives us a revealing and moving sense of the man who told so much while remaining so reticent." - Stephen Spender,

New York Times Book Review. Available March. $\$ 8.95$ 